\title{
70 ANOS DO CURSO DE PEDAGOGIA NO BRASIL: UMA ANÁLISE A PARTIR DA VISÃO DE DEZESSETE PEDAGOGOS PRIMORDIAIS
}

\author{
Giseli BarReto DA CRUZ
}

\begin{abstract}
RESUMO: A partir da visão de dezessete pedagogos primordiais, levantou-se características do início do Curso de Pedagogia e das mutações por ele experimentadas. Levantou-se, ainda, a visão predominante acerca da pedagogia enquanto domínio de conhecimento e processo de formação, para discutir a sua posição no contexto do campo acadêmico. Os participantes foram escolhidos intencionalmente, com critérios e perfis predefinidos, no sentido de assegurar a composição de um grupo representativo dos primórdios do curso e do campo da educação no Brasil. A abordagem metodológica recaiu sobre a análise de depoimentos colhidos através de entrevistas semiestruturadas. Da análise emergiram aspectos que apontam para a forma como o curso veio se construindo entre nós e para a posição conflituosa, porém importante, que foi ocupando no âmbito do espaço acadêmico da educação.
\end{abstract}

Palavras-chave: Curso de Pedagogia no Brasil. Pedagogos primordiais. Formação de pedagogos.

\section{Seventy year of Pedagogy Course in Brazil:} AN ANALYSIS BASED ON THE VIEW OF SEVENTEEN PRIMORDIAL PEDAGOGUES

ABSTRACT: Based on the view of seventeen primordial pedagogues, this study surveyed characteristics from the beginning of the course and the changes it underwent. It also points out the predominant view on pedagogy as a field of knowledge and training process to discuss its position within the academic field. Participants were deliberately chosen, from predefined profiles

* Doutora em Educação e professora adjunta do Departamento de Didática, Faculdade de Educação da Universidade Federal do Rio de Janeiro (UFRJ). E-mail: cruz.giseli@gmail.com 
and criteria, to ensure they would form a group representing the early stages of the course and of the educational field in Brazil. The methodological approach focused on the analysis of statements collected through semi-structured interviews. Such analysis revealed aspects that point out how the course has been building up among us and the conflicting, albeit important, position is has occupied in the sphere of academic education.

Key words: Pedagogy Course in Brazil. Primordial pedagogues. Pedagogue training.

\section{$\mathrm{O}$ estudo proposto}

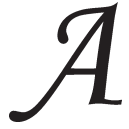

pesquisa desenvolvida investigou a trajetória e a visão de um grupo de dezessete pedagogos, considerados primordiais, sobre o início do Curso de Pedagogia no Brasil e as mutaçóes por ele sofridas, para analisar as implicaçôes, resistências e avanços na evolução desse curso e sua importância no contexto do campo acadêmico.

A pedagogia sempre foi muito questionada. Entre tantas obras, o Manifesto a favor dos pedagogos, escrito por Houssaye, Soëtard, Hameline e Fabre (Houssaye et al., 2004), situa os questionamentos que a põem em xeque, realçando que ela não precisa ser resgatada, mas respeitada. O fato é que os estudos sobre a pedagogia como produtora de saber evidenciam a perspectiva inconclusa do debate epistemológico. A dificuldade em nomear o tipo de saber que a constitui contribui para fazer consolidar no senso comum pedagógico a ideia de que lhe falta um saber próprio. Essa perspectiva interferiu, ao longo do tempo, na própria concepção e estruturação do curso de formação de pedagogos. Os estudos da história do curso, em especial o de Brzezinski (1996), o de Bissolli da Silva (1999) e o de Saviani (2008), chamam a atenção para o problema identitário da pedagogia, imersa em um curso perpassado de ambiguidades e contradições. Na literatura cresceu a discussão em torno do Curso de Pedagogia, em especial por conta do processo de definição de suas atuais diretrizes curriculares, ${ }^{1}$ acentuando, ainda mais, o tom das ideias difusas que cercam as proposições a respeito desse curso, que completa 70 anos de existência entre nós.

Ora, se dos pontos de vista teórico e histórico, a pedagogia, respectivamente, enquanto domínio de conhecimento e enquanto curso, 
mostra-se vulnerável e frágil, como situá-la no campo acadêmico? Como a pedagogia é percebida, vista, entendida em um dos campos de sua produção? Seria ela algo dispensável? Ou seria detentora de uma posição relativamente autônoma no espaço social estruturado de produção, consumo e classificação de conhecimento?

Diante desse cenário, uma questão, então, se colocou como emblemática para o estudo proposto: como se posicionam acerca do Curso de Pedagogia no Brasil aqueles pedagogos que foram testemunhas dos tempos iniciais de implantação desse curso, como seus primeiros destinatários, isto é, seus alunos, vivendo esse período? Além disso, vivendo, desde então, como "profissionais dessa área", dedicando-se a ela com empenho e com expressiva produção acadêmica, no exercício da ocupação de pedagogo, em seus diferentes aspectos e funções.

Sob esta perspectiva, o recorte da pesquisa recaiu sobre pedagogos que cursaram pedagogia no período compreendido entre os anos de 1939, quando o curso foi criado, e 1969, quando foi homologado o parecer CFE n. 252, imprimindo mudanças na composição curricular do curso. O foco se voltou para pessoas que não só graduaram-se em pedagogia nesse período, como também atuaram e/ou atuam como professores desse curso e acumulam expressivo capital científico.

Buscando colocar em evidência a posição desses pedagogos a respeito do Curso de Pedagogia no Brasil, foram definidos dois objetivos para o estudo: levantar, junto aos pedagogos investigados, aspectos característicos do início do curso e das mutaçóes por ele sofridas, para analisar as implicações, resistências e avanços na evolução desse curso e sua importância no âmbito acadêmico; e procurar obter junto a esse grupo qual a sua posição acerca da pedagogia enquanto domínio de conhecimento e enquanto curso, para mapear e interpretar a posição da pedagogia no contexto do campo educacional brasileiro.

Dessa forma, no tocante à escolha dos sujeitos participantes, o objeto do estudo apontava para uma definição intencional e proposital, com critérios e perfis predefinidos, no sentido de assegurar, tanto quanto possível, a composição de um grupo representativo dos primórdios do curso no Brasil. O procedimento de partida do estudo consistiu, então, em localizar pessoas-chave, cujas trajetórias de formação e de atuação correspondessem aos pedagogos almejados. Tratou-se de uma estratégia essencialmente voltada para a identificação de um 
70 anos do curso de pedagogia no Brasil...

conjunto de pedagogos considerados primordiais, que viveram e contribuíram, de algum modo, para o processo de consolidação da pedagogia no Brasil.

Um ponto-chave no processo de composição do grupo participante do estudo residiu na própria conceituação do que se denominou de pedagogos primordiais, no sentido amplo de terem tomado parte no período inicial do curso, mas também de se manterem atuantes e influentes desde então. Como já sinalizado, o interesse de pesquisa voltou-se para pessoas que cursaram pedagogia nas décadas de 1940, 1950 e 1960, vivenciando o curso seja na sua gênese, seja nas fases em que os primeiros marcos legais imprimiram mudanças na sua estrutura. Mas, não só isso, voltou-se, também, fundamentalmente, para pedagogos que ocupam posições dominantes no campo acadêmico porque detêm razoável capital científico. Para Bourdieu (1983), o capital científico é um tipo de capital simbólico, obtido por meio do reconhecimento concedido pelos pares, no interior do campo a que se relaciona.

Uma vez localizadas essas pessoas-chave, a abordagem metodológica foi a análise de depoimentos, colhidos através da realização de entrevistas semiestruturadas. Buscou-se, então, obter, mediante o desenvolvimento dessas entrevistas, informações sobre os primórdios do Curso de Pedagogia no Brasil, a formação nele recebida, as influências sentidas, as mutações por ele sofridas ao longo do tempo e, também, como os entrevistados percebem a pedagogia e o seu domínio de conhecimento, formação, atuação e intervenção social.

Ao iniciar as entrevistas e também após as primeiras interpretações dos dados, outras fontes complementares de informação foram consideradas. Entre elas, se situa a análise documental. Tal procedimento se desdobrou em várias frentes de investimento, de acordo com as exigências descritivas, argumentativas e interpretativas do estudo.

Sobre os pedagogos entrevistados, as entrevistas e o seu processo de análise

O grupo dos dezessete entrevistados é formado por quatorze mulheres e três homens. Nove entrevistados cursaram pedagogia na década de 1960, seis na década de 1950, um na década de 1940 e um na década de $1930 .^{2}$ Nove entrevistados são egressos de cursos oferecidos por instituições públicas e oito de instituições privadas. 
No que se refere à formação que precedeu o Curso de Pedagogia, apenas dois não passaram pela Escola Normal. Desta Escola, seis deles alcançaram a "cadeira prêmio", ingressando de imediato como professor primário efetivo do sistema de ensino do seu estado. Apenas três fizeram um curso de aperfeiçoamento, complementar ao Curso Normal, antes de ingressar no Curso de Pedagogia.

Boa parte do grupo reúne experiência como professor primário e/ou secundário. Doze atuaram como professores do primário e dez como professores do secundário na Escola Normal. No que se refere à atuação como professores do Curso de Pedagogia, todos trabalharam como formadores de pedagogos, oito deles iniciando esta experiência tão logo concluído o Curso de Pedagogia e um, em especial, começando no início da década de 1940, quando o curso foi introduzido entre nós, por meio do Decreto-Lei n. 1.190, de 4 de abril de 1939.

Todos os entrevistados fizeram algum tipo de curso de especialização no Brasil e/ou no exterior. Onze passaram pelo mestrado em educação, quatorze pelo doutorado e sete pelo pós-doutorado, sendo que alguns fizeram mais de um programa de pós-doutorado. Alguns dos entrevistados, que não registram o título de mestre e o de doutor, alcançaram direto a condição de livre-docente, pelo mérito de sua produção em uma época em que a pós-graduação não apresentava a estrutura que tem hoje.

Quase todos os entrevistados exerceram, em algum momento da sua trajetória, funçôes referentes ao ofício de pedagogo. Do grupo dos dezessete, dez entrevistados atuaram no âmbito de Secretaria Estadual de Educação, Conselho Estadual de Educação, Ministério da Educação ou órgãos a ele vinculados. Nesse contexto, boa parte do grupo, além de atuar como formador de pedagogos e de professores primários, e de se constituir como referência de pesquisa na área, pôde exercer a prática pedagoga por meio da gestão, que também foi experimentada no contexto universitário, visto que dez deles exerceram (e alguns ainda exercem) as funçôes de reitor, pró-reitor, chefe de departamento, coordenador de pós-graduação, coordenador do Curso de Pedagogia, entre outras atividades de direção acadêmica.

O processo de realização das entrevistas transcorreu no decorrer dos anos de 2006 e 2007. O roteiro estabelecido para a entrevista do tipo semiestruturada procurou, com base na questão central da pesquisa, abarcar os seguintes eixos de análise: trajetória de formação e de 
70 anos do curso de pedagogia no Brasil...

atuação do entrevistado, para evidenciar a sua condição de pedagogo primordial desde os tempos iniciais do Curso de Pedagogia; trajetória de estudante do curso, para identificar traços dos primórdios deste entre nós e das mutações por ele sofridas ao longo das suas três primeiras décadas de funcionamento; trajetória de pedagogo, de formador e de pesquisador, para perceber, aos olhos do entrevistado, de modo especial, a evoluçãa do curso e do conhecimento que o sustenta; e posições defendidas sobre a pedagogia, para discutir a natureza dos seus conhecimentos e a sua materialização em um curso.

A duração de cada entrevista variou de duas a oito horas, de acordo, principalmente, com o local de sua realização. Das dezessete entrevistas, dez foram realizadas nas residências dos entrevistados. Estas, em especial, tiveram uma duração maior. Três aconteceram em uma sala da universidade. Três foram realizadas durante a $29^{a}$ reunião anual da ANPEd, no ano de 2006. A última foi realizada durante o IX Congresso Estadual Paulista sobre Formação de Educadores, promovido pela UNESP, em 2007.

As entrevistas foram transcritas na íntegra e revisadas, após a escuta metódica de cada fita, para favorecer a conferência de fidedignidade. No processo de análise, as respostas foram organizadas em blocos, de acordo com os quatro eixos definidos no roteiro, já que a fala de cada entrevistado não seguia o mesmo encadeamento. Nesse movimento, o receio de ignorar aspectos importantes por eles abordados e que, necessariamente, não convergiam para as questões propostas forçou o trabalho concomitante com os blocos descritivos montados e com todas as demais falas.

Das trajetórias e memórias de pedagogos primordiais: os primórdios do Curso de Pedagogia no Brasil

No tocante ao seu primórdio, o resultado das análises mostrou que o Curso de Pedagogia se afirmou no seu início e, também, durante boa parte de sua trajetória como uma continuidade natural ao Curso Normal. Assim foi que, mesmo o Curso de Pedagogia tendo como uma de suas incumbências a formação de professores para a Escola Normal, além do curso ginasial, a parte referente à formação de professores foi pouco investida, recaindo o peso maior nas discussões teóricas sobre a educação. 
Sobre a parte teórica, os depoentes ressaltaram o seu peso no curso, bem maior que o da prática. Situar o papel da teoria no curso representou sublinhar a multiplicidade de saberes que constituem a pedagogia, dada a estreita relação com diferentes frentes disciplinares, sinalizando ora a força, ora a própria fraqueza da pedagogia. Se a multiplicidade de estudos teóricos faz crescer o seu domínio de conhecimento, de igual modo pode contribuir para engendrar um quadro de dispersão da própria pedagogia, dificultando a afirmação de um estatuto teórico específico.

No contexto da formação teórica obtida no curso, cinco aspectos apareceram de modo recorrente nos depoimentos, evidenciando a dinâmica predominante do curso em seus tempos iniciais: o domínio de grandes disciplinas com carga horária ampla, mas em número reduzido, facilitando o estudo aprofundado; a centralidade dos clássicos na formação; o trabalho com uma bibliografia predominantemente importada, exigindo dos alunos o domínio de diversas línguas; um alto grau de investimento no estudo para cumprir as exigências dos trabalhos acadêmicos; e a marca notadamente tradicional do curso, com aulas expositivas, trabalho meticuloso de interpretação dos textos e exames de arguição oral, tal como expressam as falas a seguir:

Fui aluna do Fernando Henrique Cardoso, quando ele era novinho e famoso já na época, porque era a menina dos olhos de Florestan Fernandes. Ele entrou na sala de aula e deu uma lista de vinte livros, sendo dez em francês e dez em inglês, e falou que no final do ano ele iria examinar um por um dos alunos sobre a leitura dos vinte livros, independentemente das demais atividades de sua disciplina. Efeito imediato! Ninguém falou: “A gente vai ter que ler tudo isto?!”. Saímos correndo, eu e parte do grupo para aprender inglês, porque já líamos francês, outros para aprender francês e outros para aprender os dois, para dar conta daquilo no decorrer do ano. E ele fez exame oral, pegou todas as nossas fichas e discutiu com cada um para ver se tinha lido mesmo. Era outra formação! (Entrevistada H-50) 3 $^{3}$

Naquele tempo, nós tínhamos que frequentar muito as bibliotecas, porque não havia muita bibliografia publicada no Brasil, e se não fosse assim não conseguíamos acompanhar o curso (...). Por exemplo, eu li $O$ belo e o sublime, de Pestalozzi, na Biblioteca Municipal aos sábados, porque durante a semana o tempo era curto para tanta atividade do curso e também porque o curso já não era de um período só, sendo na parte da manhã e em algumas tardes. (Entrevistada L-60) 
70 anos do curso de pedagogia no Brasil...

Se a teoria mobilizou o andamento do curso, a prática se afastou. Os entrevistados põem em evidência a importância dos estudos teóricos, mesmo com toda a dispersão decorrente das diferentes filiações disciplinares. Contudo, pelas várias críticas que teceram à parte prática, seja pela sua ausência, seja pela sua inconsistência, deixaram claro que seu afastamento do curso só não foi mais prejudicial à sua própria formação porque já contavam com referenciais reunidos ao longo da Escola Normal, frequentada pela maioria.

Assim, a prática, um elemento conceitual constituidor da pedagogia, parece não ter encontrado entrada no seu próprio curso. Segundo Houssaye (2004), a pedagogia pressupõe a junção mútua e dialética da teoria e da prática educativas pela mesma pessoa. Defende este autor que a articulação teoria-prática é de tal modo própria da pedagogia, que é possível identificar um pedagogo pela sua condição de prático-teórico da ação educativa. Pedagogo é aquele que, ao teorizar sobre a educação, analisa o fato educativo, mas não pára por aí, segue formulando proposições para a sua prática. Como, então, um curso que se pretende formador de profissionais para atuar nesse contexto desconsidera uma dimensão que lhe é específica?

Para Saviani (2007b), a pedagogia se desenvolveu a partir da estreita relação que estabeleceu com a prática educativa, ora sendo assumida como teoria dessa prática, ora sendo identificada como o modo por meio do qual essa prática se estabeleceria. Trata-se de uma relação conflituosa, sendo em sua essência um problema constitutivo da pedagogia, visto que a própria conceituação da pedagogia supõe a afirmação dessa relação.

Entre os componentes de formação mencionados, a pesquisa se fez presente de modo singular no curso realizado por boa parte dos entrevistados. A convivência com professores pesquisadores, participação em grupos de pesquisa, monitoria e iniciação à pesquisa, através do estudo de disciplinas como estatística, psicologia e biologia, apareceram como aspectos favoráveis à formação para o exercício desta atividade.

Junto com o aprendizado teórico e, em alguns casos, também pela pesquisa, os entrevistados ressaltaram a influência de alguns professores na sua formação. Enfatizaram que cultura, ecletismo e erudição representaram as principais marcas professorais dos formadores, que, de um modo geral, provinham das Escolas Normais, dos institutos de 
educação ou dos seminários e colégios de padres. Uma condição, em especial, referente aos professores do Curso de Pedagogia, apareceu como a principal marca do perfil dos formadores: eles não eram pedagogos. O peso de diferentes tradições disciplinares no curso contribuiu para que os formadores de pedagogos, em geral, fossem provenientes de diferentes áreas.

Das trajetórias e memórias de pedagogos primordiais: a evolução do Curso de Pedagogia no Brasil

Quanto aos aspectos observados na evolução do curso, decorrentes das mutações ocorridas, o resultado das análises apontou quatro conjuntos de diferenciais. Primeiro, aquele referente às diferenças entre as décadas de $1940 / 50$ e 60, demarcando a importância da cultura universitária. Os depoentes valorizaram, sobremaneira, a experiência vivenciada na universidade, em uma época notadamente marcada pelo ambiente altamente politizado e pelo movimento estudantil. As lutas pelas causas sociais reacenderam a importância do sujeito coletivo e da perspectiva de uma educação a serviço da transformação social, imprimindo ainda mais significado à formação acadêmica recebida.

Nós tínhamos um espaço formativo importantíssimo, que foi a militância estudantil nos plenos anos de ditadura. Eu participava de um dos movimentos, que era o da JUC - Juventude Universitária Católica, onde o tema educação era um tema-chave, que marcou muito a linha da militância. (Entrevistada J-60)

Segundo, aquele referente às diferenças observadas entre o curso de formação e o curso de atuação como formador. Nesse aspecto, os depoentes destacaram a perda da densidade teórica do curso, o papel secundarizado do estudo dos clássicos em educação, a dificuldade de construção de sínteses sobre o que é e como se elabora a pedagogia, a partir das diferentes disciplinas estudadas, e o baixo capital cultural dos alunos. Para os entrevistados, a densidade teórica, tão forte na formação que tiveram, marca predominante dos primórdios do curso entre nós, perdeu força, afetando inclusive o estudo dos clássicos, que deixaram de ocupar posição relevante no andamento do curso. Tais perdas são percebidas na problemática conceituação da própria pedagogia pelos alunos, cujo perfil vem se modificando e evidenciando a ausência 
70 anos do curso de pedagogia no Brasil...

de domínio de habilidades linguísticas e de conhecimentos gerais, entre outros, prejudicando assim o desenvolvimento das atividades acadêmicas. Para os entrevistados, o curso perdeu o que tinha de mais forte, a teoria, sem consolidar outra força capaz de favorecer o processo de afirmação de um conhecimento específico da pedagogia, tal como se depreende da fala a seguir:

Eu considero que houve um distanciamento da práxis educativa. Houve uma fragmentação grande no curso por conta de muitas disciplinas, sem que os alunos consigam fazer os nexos necessários (...). Como você olha a educação do homem grego na formação do pedagogo hoje? Estuda-se $o$ assunto, mas não se avança no seu pensamento sobre a inserção social e profissional do aluno. A práxis fica de fora... (Entrevistada J-60)

A pedagogia requer formulações próprias, a partir das diferentes áreas que lhe são constitutivas, visto que, sem a síntese integradora, o conhecimento pedagógico não se elabora. O "nexo" com a "práxis educativa”, mencionado pela entrevistada J-60, em falta no curso, é o que dá sentido ao saber pedagógico. Nem só a teoria, nem só a prática, mas a reunião mútua e dialética da teoria e da prática é o que faz emergir um pedagogo, como diz Houssaye (2004, p. 10). Para este autor,

Por definição, o pedagogo não pode ser um puro e simples prático nem um puro e simples teórico. Ele fica entre os dois, ele é o entremeio. A relação deve ser permanente e irredutível ao mesmo tempo, pois o fosso entre a teoria e a prática não pode senão subsistir (ver Soëtard, 1981). É essa fenda que permite a produção pedagógica. Por conseguinte, o prático, em si mesmo, não é um pedagogo, na maioria das vezes é um usuário de elementos, coerências ou sistemas pedagógicos. Mas o teórico da educação, como tal, também não é um pedagogo, pois não basta pensar o ato pedagógico. Só será considerado pedagogo aquele que fizer surgir um plus na e pela articulação teoria-prática em educação. Esse é o caldeirão de fabricação pedagógica.

Terceiro, aquele referente às alterações advindas do Parecer CNE n. 252, de 1969, que instituiu as habilitações na formação do pedagogo. As análises sinalizam que as habilitações são apontadas como o fator que mais mudança imprimiu ao Curso de Pedagogia. As habilitações para formar os especialistas para as atividades de orientação educacional, administração escolar, supervisão e inspeção de escolas e sistemas de ensino são questionadas pelos entrevistados, mesmo pelos que 
se consolidaram no campo como referências teóricas importantes sobre elas. Os depoentes rejeitam a concepção produtivista e a tendência tecnicista na base de sua gestação, lamentam a fragmentação observada na divisão do trabalho escolar e questionam a formação do especialista no âmbito da graduação. Entretanto, paradoxalmente, os depoimentos deixam ver que, de algum modo, as habilitações contribuíram para definir com mais clareza o papel a ser desempenhado pelo pedagogo, cuja identidade sempre se mostrou controvertida e ainda não está satisfatoriamente resolvida.

Dificilmente o pedagogo se identificou como pedagogo. Durante muito tempo o pedagogo se identificou como professor (...). Quando as habilitaçôes chegaram, chegaram com uma nomenclatura nova que foi logo assumida: "Eu sou supervisor" ou "Eu sou orientador" ou "Eu sou inspetor de ensino"... Então, ser pedagogo ficou de certa maneira em segundo plano e não disseminou a ideia de que ser pedagogo é uma precondição para ser supervisor, para ser orientador ou o que quer que seja (...). Acho que vai levar muito tempo para que essa identidade seja robustecida para que ela seja orgulhosamente assumida. (Entrevistado D-50)

As habilitações no Curso de Pedagogia tiveram o mérito de representar um dos pontos de mais difícil consenso nas discussões sobre o próprio curso, sobretudo as desencadeadas a partir da década de 1980 pelo movimento dos educadores. Extinguir, manter ou reformular fizeram do debate um embate, cujo reflexo é facilmente percebido nas diretrizes curriculares para o Curso de Pedagogia, aprovadas em abril de 2006.

Quarto, as próprias diretrizes curriculares. Os dados analisados indicam três pontos emblemáticos nos depoimentos: o afastamento da teoria, o não-lugar das habilitações e a docência como base de formação. Para os entrevistados, a perda da densidade teórica, observada no decorrer do curso, corre o risco de se acentuar com as diretrizes aprovadas, visto a diversidade de enfoques formativos que passou a vigorar no curso. No tocante às habilitações, os depoentes não consideram o seu fim como o ponto problemático do curso. Para eles, a questão mais complexa reside na formação a ser oferecida para que o pedagogo possa atuar além da sala de aula. Ser pedagogo requer fazer pedagogia, ou seja, teorizar sobre a educação, projetar, implementar, acompanhar e avaliar processos educacionais em diferentes contextos. As tradicionais 
70 anos do curso de pedagogia no Brasil...

habilitações dão lugar à docência, cuja concepção apresentada nas diretrizes curriculares busca abarcar o fazer pedagógico nas suas diferentes abrangências. Será isto possível?, questionam os depoentes. No que tange à docência como base de formação do pedagogo, a proposta, de modo geral, é aceita. Porém, existem restrições. A perspectiva de que todo pedagogo precisa entender de docência é endossada, mas a docência como base de formação não pode representar a secundarização da própria pedagogia. Para os entrevistados, o problema das diretrizes curriculares não está na docência ser ou não o fundamento principal do curso, mas no afastamento do estudo da própria pedagogia.

$\mathrm{O}$ que os pedagogos precisam fazer? O físico faz física. Ele faz avançar o conhecimento sobre a física. O biólogo faz biologia e assim por diante. Bom, o que teria que fazer o pedagogo? Teria que fazer pedagogia, ou seja, fazer crescer o conhecimento existente, o que certamente contribuiria para o crescimento da sua responsabilidade profissional. $\mathrm{O}$ curso favorecerá formação para que o pedagogo faça pedagogia? (Entrevistado D-50)

Das concepções de pedagogos primordiais: a posição do Curso de Pedagogia no contexto do campo acadêmico

De acordo com o segundo objetivo proposto, buscou-se obter junto aos investigados qual sua posição acerca da pedagogia enquanto domínio de conhecimento e enquanto curso, para mapear e interpretar a posição da pedagogia no contexto do campo acadêmico. O resultado mostrou que, para os depoentes, pensar conceitualmente sobre a pedagogia requer pensar sobre a educação. Trata-se de uma relação indissociável. A pedagogia, desde a antiguidade clássica, vem sendo pensada correlativamente à educação, justamente no que se refere ao processo de compreensão da educação e das formas pelas quais os homens identificam, (re)elaboram e fomentam entre si e nos outros os aspectos culturais que necessitam ser apropriados para a preservação da sua espécie, ou seja, da humanidade produzida historicamente pelas diferentes gerações.

Por ora, interessa ressaltar, no contexto da análise desenvolvida, que a compreensão sobre o domínio do conhecimento da pedagogia coloca-se como uma precondição, na visão dos entrevistados, 
para entender a posição da pedagogia no âmbito acadêmico, onde se insere o seu curso. A fala da entrevistada E-50 deixa ver essa posição:

A pedagogia precisa ser melhor entendida para bem do seu próprio curso. Considero que pedagogia e educação não podem ser dissociadas. A pedagogia elabora o que a educação lhe apresenta como provocação, como questão, como dúvida, como problematização. A educação, por outro lado, faz a pedagogia expandir, é o que dá sentido a ela. Uma e outra constituem um movimento interativo e permanente. Para podermos ver a educação com grandeza há que teorizar, há que pensar sobre ela, há que colocá-la sob interrogação (...). Apesar dessa relação intrínseca, que não se limita à compreensão de que uma é objeto da outra, elas não são a mesma coisa. Se fossem, não teríamos Faculdade de Educação e Curso de Pedagogia. A educação acaba sendo de tal modo abrangente, sem perder o seu centro que é a dimensão humana, que ela transborda puxando outras forças para o seu movimento. (Entrevistada E-50)

Os achados deste estudo sinalizam que, se a relação entre pedagogia e educação é incontestável, o mesmo não acontece entre pedagogia e cientificidade. Não pareceu, diante dos dados, que os depoentes neguem a possibilidade da pedagogia ser uma ciência. O que se depreendeu das análises é que os entrevistados preferem se posicionar na direção daqueles que reconhecem a pedagogia como produtora de saber, sem se ocuparem com a definição desse tipo de saber. Prevalece a tendência de compreensão da pedagogia como base de teorização da educação, o que é suficiente para lhe conferir um saber próprio. Entretanto, para os entrevistados, tal base de teorização, ao se fundamentar em saberes plurais, não pode significar nem a negação de sua própria unidade teórica, nem o contentamento com uma definição generalizadora, que pouco ou nada esclarece acerca da sua natureza e missão.

Nessa direção, veio à tona a relação entre o Curso de Pedagogia e a Faculdade de Educação. Apesar de a pedagogia ser identificada como base de teorização da e sobre a educação, tal investida não é exclusividade sua. As diferentes áreas das ciências humanas também se encarregam de teorizar sobre a educação. $\mathrm{O}$ diferencial da pedagogia em relação às demais áreas encontra-se no seu objetivo de formulação de diretrizes para a prática educativa, o que poderia lhe conferir a condição de centro formador de profissionais para a educação. Mas, para tanto, impõe-se o seu fortalecimento teórico, ainda muito dependente das contribuições de outras áreas, fazendo aparecer pouco o conhecimento que lhe é específico. 
70 anos do curso de pedagogia no Brasil...

Ainda nessa mesma direção, as análises apontam para o impacto da construção da pesquisa em educação sobre o Curso de Pedagogia. Para os depoentes, o fortalecimento da pós-graduação em educação e as pesquisas desenvolvidas por meio dela contribuíram para o crescimento do campo em várias direções, atendendo à sua própria configuração de aportar-se em múltiplas referências teóricas. Contudo, parece que não cresceu, do mesmo modo, o esforço no sentido de fazer convergir a produção de conhecimento em educação para o fortalecimento do Curso de Pedagogia.

A posição predominante entre os entrevistados parece indicar que a abertura da pós-graduação em educação para as outras áreas, trabalhando com estudantes e pesquisadores de diferentes filiaçôes disciplinares, beneficiou o aprofundamento das teorias que embasam a pedagogia. Nesse sentido, o caráter interdisciplinar da educação e, portanto, também da pedagogia foi potencializado. A esse respeito, a entrevistada A30 disse o seguinte:

A nossa pós-graduação tem uma peculiaridade que eu sempre defendi e considero muito boa: a sua abertura para as outras áreas do conhecimento. Abrir demais é complexo, fazendo correr o risco de ficar muito pulverizado. Mas é de igual modo rico, possibilitando que o conhecimento da educação se expanda. (Entrevistada A-30)

Além da abertura da pós-graduação, seu crescimento também foi apontado pelos entrevistados como um dos fatores favoráveis ao desenvolvimento do pensamento educacional. As ideias pedagógicas alcançaram maior circularidade, em especial a partir da década de 1980, quando aumentou a produção acadêmico-científica, através do avanço da pós-graduação em educação. $\mathrm{O}$ campo educacional experimentou uma significativa ampliação, não só através de cursos, mas de editoras e revistas especializadas, conferindo-lhe "um nível de amadurecimento que lhe possibilitou a conquista do respeito e reconhecimento da comunidade científica (...)" (Saviani, 2007a, p. 405).

Para os entrevistados, apesar do crescimento do campo educacional, com o avanço da pesquisa em educação, o impacto dessas pesquisas sobre o Curso de Pedagogia poderia ser mais significativo. Tal como evidenciam os depoimentos, o crescimento das pesquisas em educação contribuiu para demarcar o seu lugar no contexto acadêmico, mas o Curso de Pedagogia pouco se beneficiou dessa posição. Nessa perspectiva, o 
aproveitamento das pesquisas se configura como um dilema para os problemas educacionais, refletindo diretamente no contexto da prática pedagógica, principalmente no das escolas e dos sistemas de ensino, que protagonizam um cotidiano perpassado de uma série de conflitos, sem que as pesquisas desenvolvidas contribuam para a sua superação.

São teses e mais teses sendo construídas, dissertações e mais dissertações, pesquisas e mais pesquisas, só que um universo cada vez maior de crianças continua não aprendendo a ler e a escrever direito. Como é que é possível você admitir que a criança fique na $4^{\mathrm{a}}, 5^{\mathrm{a}}, 6^{\mathrm{a}}$ séries e não saiba ler e escrever direito? Alguma coisa está acontecendo! Onde estão os pedagogos e todo o conhecimento que se produz sobre a educação? (Entrevistado C-50)

Dessa forma, a pedagogia, mesmo detentora de saber específico, se vê, no seio das disputas acadêmicas, mais preterida que reconheci$\mathrm{da}$, dificultando a afirmação da sua posição neste campo. Diante dessas circunstâncias, pode parecer que, para os entrevistados, a pedagogia não reúne condiçôes para ser assumida dignamente no campo acadêmico. Entretanto, pelo contrário, reconhecer os limites não significa negar as possibilidades. Predomina entre os depoentes a perspectiva de que a pedagogia, mesmo não tendo estatuto científico inteiramente definido, é detentora de um corpo de conhecimentos plurais, que fundamenta os processos de formação e de atuação do pedagogo e também do professor, contribuindo, por meio das práticas desenvolvidas, para o processo mais abrangente e contínuo de transformação social.

\section{Reflexões finais}

No intuito de desenvolver uma reflexão conclusiva em face dos achados apresentados, deparo-me com algumas questões, a serem apontadas a partir de então.

Quem é o aluno de pedagogia hoje e quem são seus formadores? Certamente, estas são indagaçôes para estudos específicos. Aqui, interessa-me apenas sinalizar, no que tange aos alunos e com base exclusivamente no perfil daqueles com os quais tenho oportunidade de trabalhar, que muitos não são egressos do Curso Normal.

Tal como focalizado, o Curso de Pedagogia progressivamente assumiu a função de habilitar os professores para atuação na primeira 
70 anos do curso de pedagogia no Brasil...

etapa do ensino fundamental, constituindo-se, atualmente, como uma das três possibilidades formativas desse profissional, visto que o Curso Normal em nível médio e o Curso Normal Superior se organizam em torno da mesma finalidade. Ainda que, oficialmente, o Curso Normal não tenha sido uma precondição para o de Pedagogia, oficiosamente foi o que predominou. Uma vez que o Curso de Pedagogia destina-se basicamente à formação dos mesmos docentes habilitados pelo Curso Normal, observa-se a diminuição da oferta de vagas nesse curso e, consequentemente, o fluxo crescente de candidatos ao magistério que optam pela formação no âmbito de um curso superior.

Se, no passado, o Curso de Pedagogia considerava primordialmente os estudos teóricos em torno das disciplinas pertencentes ao campo das Ciências da Educação, não se atendo tanto quanto deveria aos pressupostos práticos para a formação dos professores do ensino secundário e dos técnicos de educação; e a habilitação conferida sem tanta formação ainda assim não era tão sentida, porque o Curso Normal, de algum modo, abordava o campo da prática, hoje o cenário é outro. Se o Curso de Pedagogia não propiciar aos alunos a formação pretendida, esta se dará no campo de atuação e nos espaços de formação continuada, que, via de regra, é pautada por programas descontínuos, sem que se identifiquem políticas articuladas a seu favor. A relação parental entre os Cursos Normal e de Pedagogia, observada nos primórdios deste curso entre nós, hoje, pode-se dizer, restringe-se ao fato de ambos habilitarem para a mesma função.

Todavia, o Curso Normal destina-se exclusivamente à formação do professor para a educação infantil e para a primeira etapa do ensino fundamental, enquanto o Curso de Pedagogia, segundo estabelecem suas diretrizes curriculares nacionais, destina-se, além disso, à formação inicial do professor para atuar nos cursos de ensino médio, na modalidade Normal; em cursos de educação profissional na área de serviços e apoio escolar e em áreas nas quais sejam previstos conhecimentos pedagógicos. Dessa forma, o Curso de Pedagogia, além de propiciar a instrumentação pedagógica específica para a docência, precisa favorecer a necessária formação teórica do pedagogo.

A amplitude dessa formação aponta para outro questionamento que emerge deste estudo. Que concepção teórico-prática conduzirá o Curso de Pedagogia, hoje, diante de tamanha abrangência? O Curso 
de Pedagogia, ao formar o professor, não pode abster-se de formar o pedagogo. E formar o pedagogo requer considerar essencialmente a dimensão teórico-prática da educação. De acordo com a investigação realizada, a teorização sobre a educação e a formação humana constituiu a força principal do Curso de Pedagogia no Brasil, em seus tempos iniciais. A análise das mutaçôes observadas no curso, ao longo dos seus 70 anos, entre nós, aponta que a teoria perdeu força, sem que outra dimensão se fortalecesse. Se o conhecimento da pedagogia se estrutura em torno da prática educativa, buscando afirmar-se como teorização dessa prática, teoria e prática da educação representam o seu eixo nuclear, a ser assumido na formação dos pedagogos. Nem só teoria, nem só prática, mas teoria e prática da educação.

Nesse sentido, considero importante demarcar que entendo e defendo o saber da pedagogia como sendo um saber composto: teoria e prática. Os saberes de base teórica são plurais, reunindo contribuições de diferentes campos conceituais. Esses saberes, quando voltados para um determinado contexto prático, cuidando de analisá-lo propositivamente, se transformam em um novo saber, não mais proveniente apenas de sua fonte de origem, mas expressão de outro saber, que é o saber pedagógico, não só de base teórica ou de base prática, mas, dialética e indissociavelmente, de base teórico-prática.

Compreendo que a educação não se constitui em um objeto de estudo específico da pedagogia. Outros campos teóricos cuidam de abordar o fenômeno educativo a partir de suas próprias concepçóes teóricometodológicas, cujas contribuiçōes são importantes e necessárias para o desenvolvimento da pesquisa educacional. A educação, enquanto objeto, deve ser investigada a partir de uma base sólida em uma das disciplinas a ela confluentes, para o bem da própria pesquisa, segundo defende Isambert-Jamati (1992). Entretanto, entendo que tal perspectiva não invalida a pedagogia como domínio de conhecimento específico sobre a educação, consolidando-se como um campo de estudos com identidades e problemáticas específicas. Recusar como válido o saber da pedagogia, em função da sua abrangência e do seu enraizamento com a prática, é negar a própria pedagogia. Se a pedagogia busca ser, em si mesma, teoria e prática da educação e, no tocante à teoria, ela é um campo caudatário de conhecimentos de diferentes afluentes, não se pode prescindir da teoria no seu curso, assim como não se pode abdicar da prática. 
Como revelam dados de pesquisa da Fundação Carlos Chagas sobre as instituições formadoras e seus currículos para a formação de professores para o ensino fundamental (Gatti e Nunes, 2009), no tocante ao Curso de Pedagogia sobressai atualmente a característica fragmentária do currículo, que tende a gerar um efeito dispersivo do processo formativo, resultando em uma formação de caráter mais abstrato e menos integrado ao campo de atuação do futuro profissional. Tal aspecto contribui para o esmorecimento da necessária conexão entre a teoria e a prática, visto que o ensino demasiadamente descritivo não possibilita, tanto quanto deveria, o exercício de relacionar adequadamente as teorias estudadas com as práticas pouco conhecidas e elaboradas. $\mathrm{O}$ resultado são pedagogos docentes que revelam conhecimentos insuficientes sobre o seu próprio ofício.

Com efeito, há que se tirar proveito da diversidade teórica que envolve a pedagogia. Ela não pode resultar em desarticulação das disciplinas e em um estudo dissociado da realidade educacional. Pelo contrário, a trajetória histórica da pedagogia, tal como apontaram os sujeitos desta pesquisa, precisa ser estudada no seu próprio curso, em diálogo com as várias abordagens sobre a educação, contribuindo para o fortalecimento do domínio que lhe é específico. Nessa linha de raciocínio, o aprofundamento teórico, pela via das diferentes disciplinas, precisa considerar a educação como prática social e o trabalho pedagógico e docente como a referência primeira da pedagogia e, consequentemente, do seu curso. O tratamento específico dos conhecimentos educacionais, a partir da lógica de cada disciplina e de seu professor, precisa se ligar ao estudo, à reflexão e à pesquisa sobre a educação como prática social, propiciando aos pedagogos em formação fundamentos para teorizar sobre suas práticas e condições para submetê-las à discussão.

\section{Recebido em janeiro de 2009 e aprovado em setembro de 2009.}

\section{Notas}

1. Resolução do Conselho Nacional de Educação, n. 1, de 10 de abril de 2006, identificadas nos Pareceres CNE/CP n. 5/2005 e n. 3/2006.

2. Uma indicação para a década de 1930 refere-se a um egresso do curso de História e Geografia da FFCL/USP (1937-1940). O Curso de Pedagogia, enquanto graduação, não se encontra na sua trajetória, o que levou a um desvio na composição do grupo de participantes da pesquisa. Todavia, seu percurso o colocou na condição de quem viveu, de fato, os 
primórdios da pedagogia no Brasil, visto que integrava o corpo docente da FFCL/USP, quando o curso se instalou ali. Por esta razão, entendeu-se que seu depoimento não poderia deixar de compor o quadro pretendido com o estudo.

3. A identificação dos entrevistados ocorrerá por meio de uma letra alfabética seguida da numeração da década em que o mesmo cursou pedagogia.

\section{Referências}

BISSOLLI DA SILVA, C.S. Curso de pedagogia no Brasil: história e identidade. Campinas: Autores Associados, 1999.

BOURdieU, P. O campo científico. In: Ortiz, R. (Org.). Pierre Bourdieu. São Paulo: Ática, 1983. p. 122-155.

BRZEZINSKI, I. Pedagogia, pedagogos e formação de professores: busca e movimento. Campinas: Papirus, 1996.

GATTI, B.A.; NUNES, M.M.R. (Org.). Formação de professores para o ensino fundamental: estudo de currículos das licenciaturas em pedagogia, língua portuguesa, matemática e ciências biológicas. São Paulo: Fundação Carlos Chagas, 2009.

HOUSSAYE, J. et al. Manifesto a favor dos pedagogos. Porto Alegre: ARTMED, 2004.

HOUSSAYE, J. Pedagogia: justiça para uma causa perdida? In: Houssaye, J. et al. Manifesto a favor dos pedagogos. Porto Alegre: ARTMED, 2004. p. 9-45.

ISAMBERT-JAMATI, V. Ciências da educação: um plural importante quando se trata de pesquisa. Teoria \& Educação, Porto Alegre, n. 5, p. 170-173, 1992.

SAVIANI, D. História das idéias pedagógicas no Brasil. Campinas: Autores Associados, 2007a.

SAVIANI, D. Pedagogia: o espaço da educação na universidade. Cadernos de Pesquisa, São Paulo, v. 37, n. 130, p. 99-134, jan. $2007 \mathrm{~b}$.

SAVIANI, D. A pedagogia no Brasil: história e teoria. Campinas: Autores Associados, 2008. 